\title{
Comparisons of Two-level Discectomy and Fusion with Cage Alone versus Single-level Corpectomy and Fusion with Plate in the Treatment of Cervical Degenerative Disc Disease
}

\author{
Bok Young Ha, Hong Bo Sim, In Uk Lyo, Eun Suk Park, Soon Chan Kwon, Jun Bum Park \\ Department of Neurosurgery, Ulsan University Hospital, University of Ulsan College of Medicine, Ulsan, Korea
}

Objective: To compare the radiologic parameters and clinical outcomes of two-level anterior cervical discectomy and fusion (ACDF) with cage alone versus single-level anterior cervical corpectomy and fusion (ACCF) with plate in the treatment of two-level contiguous cervical degenerative disc disease.

Methods: Of all 38 consecutive patients who were included in this study, 22 patients underwent on a two-level contiguous ACDF with cage alone (ACDF-CA group), 16 patients underwent a single-level ACCF with plate (ACCF-P group). We compared following parameters between these two groups; perioperative parameters (hospital stays, blood loss and operation duration), clinical parameters (Japanese Orthopedic Association scores and Odom's criteria) and radiologic parameters segmental height ratio (SHR), segmental lordotic angle (SLA), global lordotic angle (GLA) and fusion rate).

Results: The amount of operative blood loss in the ACCF-P group was higher than in the ACDF-CA group with statistical significance $(p<0.05)$. Clinical outcomes and fusion rates were similar between groups. The postoperative SHRs in both groups were higher than that of preoperative period with statistical significance; however, these values significantly decreased at the last follow up period. The SLA increased during the immediate postoperative period, and then mild decreased. The values of GLA in both groups did show variable differences according to each time frame.

Conclusion: The results of ACDF-CA were comparable with ACCF-P with regard to clinical and radiologic outcomes in contiguous two-level cervical fusion. A two-level ACDF-CA as a treatment modality for two-level contiguous cervical disc disease may be a worthwhile method as an alternative to single-level ACCF-P.

Key Words: Cervical spine $\cdot$ Spondylosis $\cdot$ Spinal fusion $\cdot$ Cage $\cdot$ Plate

\section{INTRODUCTION}

Cervical degenerative disc disease is a common cause of neck pain, radiculopathy or myelopathy. Many surgeons have recommended surgical decompression for the treatment of cervical spondylosis associated with medically intractable radiculopathy or myelopathy. Since the publication of a report by Smith and Robinson ${ }^{16}$, anterior cervical discectomy and fusion (ACDF) has been widely accepted as the golden standard for surgical treatment of cervical degenerative disc disease. However, its success rate declines in multi-level discectomies as the number of operated levels increases ${ }^{3}$. The optimal surgical treatment, therefore, still remains controversial for the patient with multi-level

- Received: April 13, 2012 - Revised: September 4, 2012

- Accepted: September 26, 2012

Corresponding Author: Hong Bo Sim, MD, PhD

Department of Neurosurgery, Ulsan University Hospital, 290-3 Jeonha-

Dong, Dong Gu, Ulsan 682-714, Korea

Tel: +82-52-250-7139, Fax: +82-52-250-7138

Email:nssim01@gmail.com cervical spondylosis. They can be treated with either multi-level ACDF or anterior cervical corpectomy and fusion (ACCF). However, it is also not clear whether multi-level cervical spondylosis is the best treated with multi-level ACDF or single/multilevel ACCF.

Clinical results of the application of interbody cages to the multi-level ACDF in patients with cervical degenerative disc disease have been encouraging ${ }^{6,18,20)}$. Further, ACDF with cage alone has been reported to have produced relatively good results $3,8,9,11,19,21)$. However, controversy remains with regard to fusion rate, subsidence, pseudoarthrosis in association with ACDF with cage alone compared with plate augmentation in $\mathrm{ACDF}^{5}$. There have few studies on two-level contiguous ACDF reporting that the results of ACDF with cage alone would be comparable with ACDF with plate ${ }^{8,9,11,19)}$. However, the National Health Insurance Corporation does not approve of two-level contiguous ACDF with cage alone on the ground of cost effectiveness and lack of evidences for positive clinical results. Therefore, many spine surgeons usually practice singlelevel ACDF with cage alone. However, ACCF with plate instru- 
ment is the usual choice of treatment of two-level contiguous cervical disc disease since ACDF with cage alone is not applicable in such cases.

There are few comparative studies of two-level contiguous ACDF and single-level ACCF with plate augmentaion ${ }^{13,14,22)}$. However, there is no direct comparison between two-level ACDF with cage alone and single-level ACCF with plate instrument. The purpose of this study was to compare the perioperative, clinical and radiologic parameters between the two operation methods, two-level ACDF with cage alone and singlelevel ACCF with plate, in the treatment of two-level contiguous cervical degenerative disc disease.

\section{MATERIALS AND METHODS}

We retrospectively reviewed the records of 75 patients who underwent two-level contiguous anterior cervical fusion from September 2002 to August 2010. Among them, patients with less than 6 months of postoperative follow-up were excluded from this study. Other patients who had severe trauma, infectious or neoplastic cases, or underwent combined posterior or other procedures were also excluded. Only 38 patients who had cervical degenerative disc disease were included in this study. Subjects were divided into two groups. 22 patients underwent two-level contiguous ACDF with cage alone (ACDF-CA group) and 16 patients underwent single-level ACCF with plate instrumentation (ACCF-P group) for the treatment of cervical degenerative disc disease. Indication for surgery included intractable radiculopathy, myelopathy, or a combination of the two, due to nerve root or spinal cord compression. The cervi-

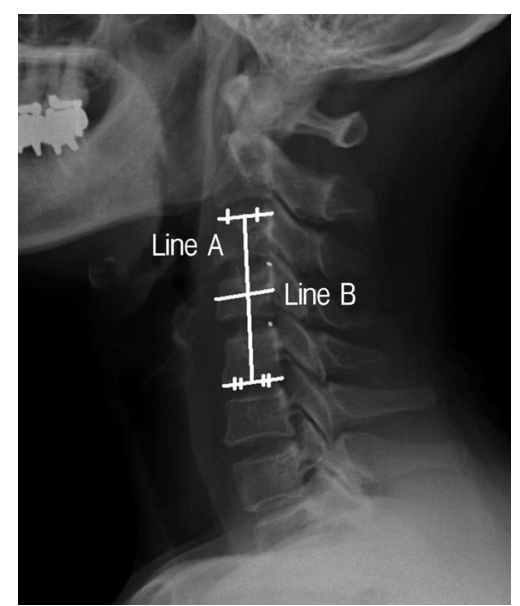

Fig. 1. Lateral radiograph of cervical spine showing the segmental height ratio (SHR) measuring method. Segmental height ratio=segmental height (line A)/AP diameter of the mid vertebral body (line B). cal spondylosis and degenerative disease was diagnosed by means of cervical X-ray, computed tomography and magnetic resonance imaging.

The choice of operation was dependent on the presence or absence of retrovertebral compression. Corpectomy was chosen if the compression was considered to be removed more easily using it, and it was also considered the patients with a large posterior osteophyte adjacent to end plate. Otherwise, ACDF was chosen. Surgical procedure was performed according to the standard anterior approach described by Smith and Robinson $^{16}$. All the patients in the ACDF-CA groups underwent two-level contiguous ACDF without anterior plate. In all 22 patients in the ACDF-CA group, an optimal PEEK cage filled with allograft (12 patients) or autograft (10 patients) bone was used. In ACCF-P group, 13 patients were treated by inserting a mesh cage which was filled with autograft (10 patients) or allograft (3 patients) bone. Autologous iliac bone block was also used in 3 patients. A Philadelphia collar placed in all patients in both groups for 6-8 weeks postoperatively.

Radiological follow-up was performed during the preoperative period and 1 day and 3 months postoperatively, as well as during the last follow-up visit. Lateral X-rays were used to evaluate the cervical spinal curve and the height ratio of fused segments. Segmental height ratio (SHR) was measured by dividing the segmental height of fused segments by antero-posterior diameter of the mid-vertebral body (Fig. 1). Segmental lordotic angle (SLA) was measured using Cobb's angle between the upper endplate of the most cranial vertebral body and the lower endplate of the most caudal vertebral body of the fused segments (Fig. 2). Global lordotic angle (GLA) was measured using Cobb's angle between the inferior endplate of the $\mathrm{C} 2$ ver-

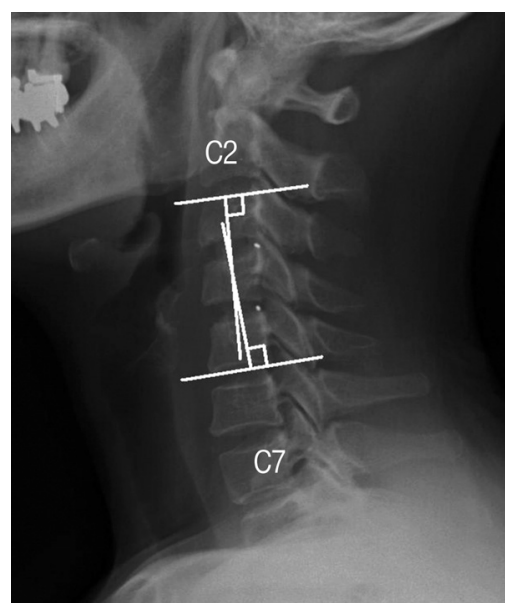

Fig. 2. Lateral radiograph of cervical spine showing the segmental lordotic angle (SLA) measuring method. There is a Cobb's angle between the upper endplate of the vertebral body and the lower endplate of vertebral body of the fused segment. 


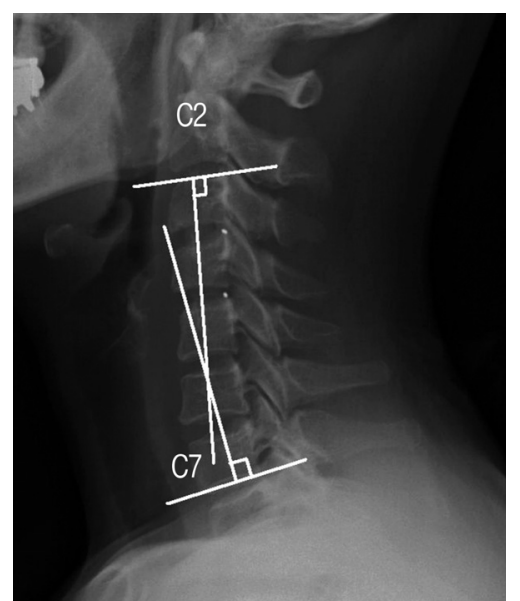

Fig. 3. Lateral radiograph of cervical spine showing the global lordotic angle (GLA) measuring method. There is a Cobb's angle between the lower endplate of the C2 vertebral body and the lower endplate of C7 vertebral body.

tebral body and the inferior endplate of the $\mathrm{C} 7$ vertebral body (Fig.3).

Subsidence was defined as a graft material subsided more than $3 \mathrm{~mm}$ into the adjacent vertebral endplate on lateral plain radiographs. Fusion was defined as the absence of motion on flexion/extension radiographs and the absence of any dark halo around graft bone or cages, or presence of bridging bone anterior or posterior to cages or bone graft. Clinical follow-up was performed consisting of standard neurosurgical examinations and evaluations using Japanese Orthopedic Association (JOA) score and Odom's criteria.

We compared following parameters between the two groups; perioperative parameters (hospital stays, blood loss and operation duration), clinical parameters (JOA scores and Odom's criteria) and radiologic parameters (SHR, SLA, GLA and fusion rate). Data were recorded and statistical analysis performed using SPSS 19.0 (SPSS Inc., Chicago, IL, USA). Data were presented as mean \pm standard deviation. Since the number of specimens was limited and the data could not be assumed to be normally distributed, Mann-Whitney rank sum and Chi-Square test were used to analyze the differences in perioperative parameters and clinical outcomes between groups. For radiologic parameters, comparison between two groups was performed using Mann-Whitney test. Comparison between the results for each time frame within each group was performed using Wilcoxon signed ranks test because the number of specimens was small; however, comparison between the results for each time frame of total specimens for each parameter was performed using paired t-test because there was sufficient number of specimens which were normally distributed. Significance of difference was determined when the probability level $\mathrm{p}<0.05$.
Table 1. Summary of demographic data of patients

\begin{tabular}{lll}
\hline \hline & ACDF-CA group & ACCF-P group \\
\hline Number of patients & 22 & 16 \\
Age (year) & $56.5 \pm 16.5$ & $57.1 \pm 15.0$ \\
Sex (male/female) & $12 / 10$ & $11 / 5$ \\
Operation segment & & \\
C3/4/5 & 3 & 2 \\
C4/5/6 & 9 & 6 \\
C5/6/7 & 10 & 8 \\
Radiculopathy/Myelopathy & $13 / 9$ & $5 / 11$ \\
Follow up period (month) & $27.5 \pm 12.3$ & $22.7 \pm 9.7$ \\
\hline
\end{tabular}

Note; data are represented as mean \pm standard deviation or the number of patients

\section{RESULTS}

ACDF-CA group consisted of 12 males and 10 females with mean age $56.5 \pm 16.5$ years. Among them, 13 patients had radiculopathy and 9 patients had myelopathy. Duration of the follow up period was $27.5 \pm 12.3$ months. ACCF group consisted of 11 males and 5 females with mean age $57.1 \pm 15.0$ years. Among them, 5 patients had radiculopathy and $11 \mathrm{pa}-$ tients had myelopathy. Mean follow-up period was 22.7 \pm 9.7 months. Demographic information of the patients and their locations of treated levels are shown in Table 1.

\section{Perioperative parameters}

Duration of hospital stay was $18.13 \pm 10.0$ days for patients in ACDF-CA group and 23.81 \pm 12.4 days for patients in ACCF-P group with no statistically significant intergroup difference. Mean blood losses during operation were estimated to be about $115.5 \pm 14.5 \mathrm{cc}$ for ACDF-CA group and 148.5 \pm $12.4 \mathrm{cc}$ for ACCF-P group. The amount of blood loss in the ACCF-P group was higher than that of the ACDF-CA group during operation with statistical significance $(p<0.05)$. The mean duration of operation was 147.5 \pm 72.5 minutes for ACDF-CA group and 177.5 \pm 52.5 minutes for ACCF-P group. The patients in ACCF-P group seemed to have required longer times for operation than that those in ACDF-CA group, with no statistically significant difference, however (Table 2).

\section{Clinical parameters}

For all patients in two groups, mean JOA score was 14 points preoperative and 15 points postoperative with no statistically significant difference. Postoperative outcome was shown to 
Table 2. Comparison of perioperative parameters between two groups

\begin{tabular}{lccc}
\hline \hline & $\begin{array}{c}\text { ACDF-CA } \\
\text { group }\end{array}$ & $\begin{array}{c}\text { ACCF-P } \\
\text { group }\end{array}$ & p-value \\
\hline Hospital stay (days) & $18.13 \pm 10.0$ & $23.81 \pm 12.4$ & 0.312 \\
Blood loss (cc) & $115.5 \pm 14.5$ & $148.5 \pm 18.5$ & 0.000 \\
$\begin{array}{l}\text { Operation duration } \\
\text { (mins) }\end{array}$ & $147.5 \pm 72.5$ & $177.5 \pm 52.5$ & 0.258 \\
\hline
\end{tabular}

Note; data are represented as mean \pm standard deviation. p-values were derived from comparison between groups using MannWhitney test.

Table 3. Comparison of clinical parameters between two groups

\begin{tabular}{lllr}
\hline \hline & $\begin{array}{c}\text { ACDF-CA } \\
\text { group }\end{array}$ & $\begin{array}{c}\text { ACCF-P } \\
\text { group }\end{array}$ & p-value \\
\hline Mean JOA score & & & \\
Preoperative & 14 & 14 & 0.404 \\
Postoperative & 15 & 15 & 0.781 \\
Odom's criteria & & & \\
Excellent & $8(36 \%)$ & $4(25 \%)$ & 0.001 \\
Good & $14(64 \%)$ & $11(68)$ & $<0.001$ \\
Fair & 0 & 0 & \\
Poor & 0 & $1(6 \%)$ & \\
Total & & & 0.408 \\
\hline
\end{tabular}

Note; data are represented as the number of patients (\% of group). The p-values of JOA score were derived from comparison using Mann-Whitney test. The p-values of Odom's criteria were derived from comparison Chi-Square test. be higher by one point in both groups (Table 3). Evaluation of Odom's criteria revealed that all patients except one in both groups clinically improved. However, worsening occurred in one patient who underwent ACCF-P procedure. There also was no statistically significant difference between groups.

Postoperative complications were observed transient hoarseness in the each 2 cases of both groups, hardware related complications were developed a case of screw loosening in ACCF-P, they were not in the ACDF-CA group (Table 4).

\section{Radiologic parameters}

A summary of radiologic outcomes is shown in Fig. 4 and Table 5. SHR increased during immediate postoperative period in both groups. However, it progressively decreased during fol-

Table 4. Summary of postoperative complications

\begin{tabular}{lcc}
\hline \hline & $\begin{array}{c}\text { ACDF-CA } \\
\text { group }\end{array}$ & $\begin{array}{c}\text { ACCF-P } \\
\text { group }\end{array}$ \\
\hline $\begin{array}{l}\text { Hardware related } \\
\text { cage migration }\end{array}$ & 0 & - \\
screw loosening & - & 1 \\
Donor site related & 1 & 1 \\
Others & & \\
injury of spinal cord/root & 0 & 1 \\
infection & 0 & 0 \\
wound hematoma & 1 & 0 \\
temporary hoarseness & 2 & 2
\end{tabular}

Table 5. Comparison between each time frame

\begin{tabular}{|c|c|c|c|c|}
\hline \multirow{2}{*}{ Value } & \multirow{2}{*}{ Time frame } & \multicolumn{3}{|c|}{ p-value } \\
\hline & & ACDF-CA group & ACCF-P group & Total \\
\hline \multicolumn{5}{|l|}{ SHR } \\
\hline & Preop vs imm. postop & 0.001 & 0.020 & 0.000 \\
\hline & Preop vs last follow up & 0.189 & 0.642 & 0.174 \\
\hline & Postop vs last follow up & 0.028 & 0.026 & 0.002 \\
\hline \multicolumn{5}{|l|}{ SLA } \\
\hline & Preopvs imm. postop & 0.115 & 0.196 & 0.041 \\
\hline & Preop vs last follow up & 0.783 & 0.408 & 0.487 \\
\hline & Postop vs last follow up & 0.291 & 0.679 & 0.222 \\
\hline \multicolumn{5}{|l|}{ GLA } \\
\hline & Preop vs imm. postop & 0.305 & 0.679 & 0.608 \\
\hline & Preop vs last follow up & 0.615 & 0.638 & 0.937 \\
\hline & Postop vs last follow up & 0.506 & 0.918 & 0.608 \\
\hline
\end{tabular}

SHR, segmental height ratio; SLA, segmental lordotic angle; GLA, global lordotic angle; Preop, preoperative period; Imm. Postop, immediate postoperative period. The p-values were derived from comparison within group using Wilcoxon signed ranks test; totals were derived using paired $T$ test. 

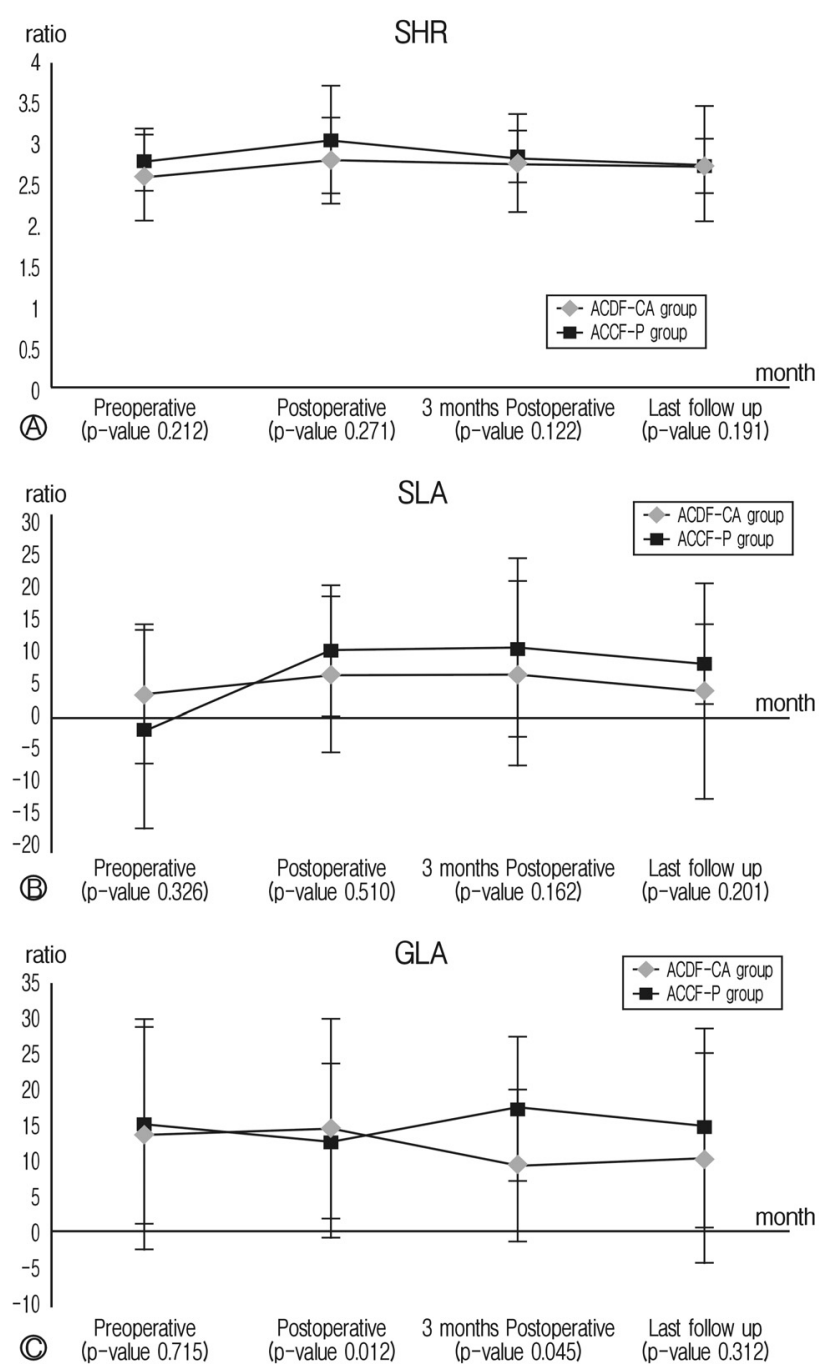

Fig. 4. Line graphs showing comparisons of radiologic parameters between two groups. There are segmental height ratio $(A)$, segmental lordotic angle (B) and global lordotic angle (C). Data are represented as mean \pm standard deviation. The $p$-values were derived from comparison between groups using Wilcoxon signed ranks test.

low up period. Preoperative, immediate postoperative and last follow-up SHR was $2.64 \pm 0.57,2.81 \pm 0.52$ and $2.77 \pm 0.72$, respectively, in ACDF-CA group and $2.79 \pm 0.35,3.06 \pm 0.67$ and $2.74 \pm 0.33$, respectively, in ACCF-P group. Immediate postoperative SHR was higher than that of preoperative time $(\mathrm{p}=0.001$ for the ACDF-CA, 0.020 for the ACCF-P group) with statistical significance. However, it decreased significantly at the last follow-up period ( $\mathrm{p}=0.028$ for ACDF-CA group, 0.026 for ACCF-P group). SHR decreased more in ACCF-P group than in ACDF-CA group. But it did not show statistically significant difference between the two groups. Comparing with immediate postoperative period, more than $3 \mathrm{~mm}$ subsidence occurred in 7 segments (16\%) of total 44 segments of ACDF-CA group, in 2 segments (13\%) of 16 segments of ACCF-P group. Among them, there was no case with clinical worsening.

SLA increased during the immediate postoperative period compared with preoperative period. But it did not show statistically significant difference between groups and between each time frame within the same group except the total comparison between preoperative and immediate postoperative periods. There were also no statistically significant differences between groups and between each time frame within the same group. GLA in ACDF-CA group was significantly larger than that in ACCF-P group during immediate postoperative period $(\mathrm{p}=0.012)$. However, GLA in ACCF-P group was significantly larger than that in ACDF-CA group in 3 months postoperative. Other values of GLA did not show statistical significant differences between groups and between each time frame within the same group.

All patients included in the two groups of this study showed fusion except one in simple X-ray. A case of ACDF-CA group was suspected psuedoarthrosis. However, she is clinically stable; our observation is still ongoing more than 1 year.

\section{DISCUSSION}

Surgical treatment of multi-level cervical spondylosis is a challenging process. The optimal surgical treatment for the patient with multi-level cervical spondylosis still remains controversial. The choice of surgical treatment could be either multi-level ACDF or ACCF. It is also not clear which of multi-level ACDF or single/multi-level ACCF is better surgical treatment for multi-level cervical spondylosis. Compared with multi-level ACDF, ACCF has resulted in high fusion rates because there are only two fusion surfaces ${ }^{4,10)}$. ACCF is also associated with early hardware failure ${ }^{15)}$. To overcome these problems, various methods and instruments for anterior cervical spine fusion have been developed. Recently, the use of anterior cervical plate with or without cage in ACCF and ACDF procedures has become popular and been regarded as a standard practice.

In multi-level ACDF, augmentation with plate fixation may seem preferable due to higher fusion and lower reoperation rates and better clinical outcomes, ${ }^{3,23)}$. In spite of these benefits, plate-related complications including screw pullout, screw breakage, injury of laryngeal nerve, injury of esophagus, prolonged dysphagia, injury of cord or root and wound infection occurred at varied rates from 2.2 to $24 \% \%^{2,3)}$. Additionally, operation using plate fixation usually takes longer ${ }^{9,19)}$. The clinical results of the applications of interbody cages in multilevel ACDF have been encouraging ${ }^{6,18,20)}$. Furthermore, ACDF with cage alone has been reported with relatively good re- 
BY $\mathrm{Ha}$, et al.

Table 6. Comparative studies of ACDF and ACCF for cervical spondylosis

\begin{tabular}{|c|c|c|c|c|c|}
\hline year & Author & decompression & reconstruction & Clinical outcome & Fusion rate \\
\hline 1985 & Yonenobu et al. ${ }^{25)}$ & $\begin{array}{l}\text { Multilevel ACDF vs } \\
\text { corpectomy }\end{array}$ & autograft & Superior with Corpectomy & Superior with Corpectomy \\
\hline 1997 & Swank et al. ${ }^{17)}$ & $\begin{array}{l}\text { Multilevel ACDF vs } \\
\text { corpectomy }\end{array}$ & $\begin{array}{l}\text { Allograft and } \\
\text { autograft }\end{array}$ & Superior with Corpectomy & Superior with Corpectomy \\
\hline 2001 & Wang et al. ${ }^{22)}$ & $\begin{array}{l}\text { Two-level ACDF vs } \\
\text { corpectomy }\end{array}$ & allograft & Equivalent & Equivalent \\
\hline 2004 & Nirala et al. ${ }^{12)}$ & $\begin{array}{l}\text { Multilevel ACDF vs } \\
\text { corpectomy }\end{array}$ & autograft & Superior with Corpectomy & Superior with Corpectomy \\
\hline 2007 & Hwang et al. ${ }^{7)}$ & $\begin{array}{l}\text { Multilevel ACDF vs } \\
\text { corpectomy }\end{array}$ & $\begin{array}{l}\text { Allograft and } \\
\text { autograft }\end{array}$ & Equivalent & Equivalent \\
\hline 2009 & Oh et al. $^{13)}$ & $\begin{array}{l}\text { Two-level ACDF vs } \\
\text { corpectomy }\end{array}$ & autograft & Equivalent & Equivalent \\
\hline 2009 & Uribe et al. ${ }^{20)}$ & $\begin{array}{l}\text { Multilevel ACDF vs } \\
\text { corpectomy }\end{array}$ & autograft & Equivalent & Equivalent \\
\hline 2010 & Park et al. ${ }^{14)}$ & $\begin{array}{l}\text { Two-level ACDF vs } \\
\text { corpectomy }\end{array}$ & allograft & None reported & None reported \\
\hline
\end{tabular}

sults $3,8,9,11,19,21)$. However, controversy over ACDF with cage alone remains with regard to its fusion rate, subsidence and pseudoarthrosis compared with plate augmentation in $\mathrm{ACDF}^{5)}$. There have been few studies reporting that the results of ACDF with cage alone would be comparable with those of ACDF with plate in two-level contiguous $\mathrm{ACDF}^{8,9,11,19)}$. Lee et al. ${ }^{9)}$ reported that the use of two-level stand alone cages in ACDF yielded excellent fusion rate and clinical outcomes in spite of subsidence. Joo et al. ${ }^{8)}$ suggested that routine use of plate and screw in two-level ACDF may not be beneficial.

To the best of our knowledge, there have been a few studies comparing single/multi-level ACCF and ACDF in terms of clinical results and fusion rates (Table 6$)^{7,9,13,14,17,20,22,25)}$. In early reported series ${ }^{12,17,23,25)}$, ACCF showed superior results compared with ACDF except in one report. Interestingly, Wang et al. $^{22)}$ reported that the addition of cervical plates in either two-level disectomies or single-level corpectomy yielded similar clinical results and fusion and complication rates. It may be because comparison was made only between single-level ACCF and two-level ACDF and because anterior plate augmentation was used. However, in recent reported series ${ }^{7,13,20)}$, these two procedures yielded similar results in terms of fusion rate and clinical outcomes. We suggest that their observations be used as valuable references in using and developing instruments such as plate or cage in ACCF and ACDF procedures.

Hwang et al. ${ }^{7}$ reported that the absence of donor site complications and construct failures as well as shorter hospital stay would render the multi-level ACDF with cage and plate fixation preferable to ACCF with strut graft and plate fixation. Oh et al. ${ }^{13)}$ reported that, although these two surgical procedures were found to be similar to each other in terms of clini- cal outcomes, two-level ACDF was found to be superior to single-level ACCF in terms of operation duration, amount of bleeding, preserved segmental height and postoperative cervical lordosis. Uribe et al. ${ }^{20)}$ postulated that ACCF resulted in a higher rate of early hardware failure and psudoarthroses than ACDF, and thus in the absence of pathology requiring removal of vertebral body, ACDF could result in lower morbidity. Park et al. ${ }^{14)}$ observed that graft subsidence and the loss of cervical lordosis appeared to occur mainly during the first 6 weeks after the surgery in both procedures. ACCF continued to subside at the posterior portion of caudal end plateeven after 6 weeks. However, the results of our study are some what different from others. They used a plate augmentation either in ACDF or ACCF. Surgical procedures in our study, however, were performed without plate in ACDF or with plate in ACCF. According to our retrospective review, in two-level contiguous cervical fusion, ACDF-CA was comparable with ACCF-P with regard to clinical and radiologic results with no significant difference. However, significant differences were observed between these two groups in terms of blood loss. Judging from the result of SHR, subsidence progressed after the surgery with statistically significant difference between the two groups. Segmental height decreased more in ACCF-P group than in ACDF-CA group without statistically significant difference. SLA is mildly reduced in similar pattern as SHR, postoperatively. Despite decreases in segmental height and segmental lordosis, they did not affect global cervical lordosis. These results support the observation that graft subsidence is not correlated with sagittal alignment and clinical outcome ${ }^{1,14)}$, and that global cervical lordosis is correlated with clinical outcomes ${ }^{24)}$. Our results, variable values of 
GLA according to time frame, represent that global cervical lordosis is correlated with clinical outcomes. All patients of both groups showed fusion except one in simple X-ray. These results are relatively higher than others. We are thinking about possibility of that our fusion rates are likely to have been overestimated because of inclusion criteria of this study. They are that the patients with less than 6 months of postoperative follow-up and underwent combined posterior procedures were excluded from this study. Indeed, three cases with posterior combined procedures, 2 early hardware failures and 1 early collapse were excluded from this study.

There are some limitations in this study. Short follow-up period and a small number of subjects did not allow thorough evaluation. Being a retrospective study, it was not performed as a randomized, controlled trial study. Therefore, long term follow-up and a prospective randomized study including a large subject population are required in the future.

\section{CONCLUSION}

Our results suggest that there are no clear benefits of ACCF$\mathrm{P}$ over ACDF-CA in terms of clinical and radiologic outcomes in two-level contiguous cervical fusion. However, two-level ACDF-CA was found to be superior to ACCF-P in terms of the amount of bleeding. Therefore, we conclude that two-level ACDF-CA may be a worthwhile method and may be used as an alternative to single-level ACCF-P, in the absence of retrovertebral compression, as a treatment modality for two-level contiguous cervical disc disease.

\section{REFERENCES}

1. Cloward RB: Complications of anterior cervical disc operation and their treatment. Surgery 69:175-182, 1971

2. Das K, Couldwell WT, Sava G, Taddonio RF: Use of cylindrical titanium mesh and locking plates in anterior cervical fusion. Technical note. J Neurosurg 94:174-178, 2001

3. Demircan MN, Kutlay AM, Colak A, Kaya S, Tekin T, Kibici $\mathrm{K}$, et al: Multilevel cervical fusion without plates, screws or autogenous iliac crest bone graft. J ClinNeurosci 14:723-728, 2007

4. Emery SE, Bohlman HH, Bolesta MJ, Jones PK: Anterior cervical decompression and arthrodesis for the treatment of cervical spondylotic myelopathy. Two to seventeen-year follow-up. J Bone Joint Surg Am 80:941-951, 1998

5. Ha SK, Park JY, Kim SH, Lim DJ, Kim SD, Lee SK: Radiologic assessment of subsidence in stand-alone cervical polyetheretherketone (PEEK) cage. J Korean NeurosurgSoc 44:370-374, 2008

6. Hacker RJ, Cauthen JC, Gilbert TJ, Griffith SL: A prospective randomized multicenter clinical evaluation of an anterior cervical fusion cage. Spine (Phila Pa 1976) 25:2646-2654, 2000
7. Hwang SL, Lee KS, Su YF, Kuo TH, Lieu AS, Lin CL, et al: Anterior corpectomy with iliac bone fusion or discectomy with interbody titanium cage fusion for multilevel cervical degenerated disc disease. J Spinal Disord Tech 20:565-570, 2007

8. Joo YH, Lee JW, Kwon KY, Rhee JJ, Lee HK: Comparison of fusion with cage alone and plate instrumentation in two-level cervical degenerative disease. J Korean Neurosurg Soc 48:342346,2010

9. Lee HB, Lee SG, Park CW, Yoo CH, Kim SM, Kim WK: Twolevel anterior cervical disectomy and fusion with stand- alone cagw in cervical spinal degerativediseae. Korean J Spine 6:124130, 2009

10. McAfee PC, Bohlman HH, Ducker TB, Zeidman SM, Goldstein JA: One-stage anterior cervical decompression and posterior stabilization. A study of one hundred patients with a minimum of two years of follow-up. J Bone Joint Surg Am 77:1791-1800, 1995

11. Moon HJ, Kim JH, Kim JH, Kwon TH, Chung HS, Park YK: The effects of anterior cervical discectomy and fusion with stand-alone cages at two contiguous levels on cervical alignment and outcomes. ActaNeurochir (Wien) 153:559-565, 2011

12. Nirala AP, Husain M, Vatsal DK: A retrospective study of multiple interbody grafting and long segment strut grafting following multilevel anterior cervical decompression. $\mathrm{Br} \mathrm{J}$ Neurosurg 18: 227-232, 2004

13. Oh MC, Zhang HY, Park JY, Kim KS: Two-level anterior cervical discectomy versus one-level corpectomy in cervical spondylotic myelopathy. Spine (Phila Pa 1976) 34:692-696, 2009

14. Park Y, Maeda T, Cho W, Riew KD: Comparison of anterior cervical fusion after two-level discectomy or single-level corpectomy: sagittal alignment, cervical lordosis, graft collapse, and adjacent-level ossification. Spine J 10:193-199, 2010

15. Sasso RC, Ruggiero RA Jr, Reilly TM, Hall PV: Early reconstruction failures after multilevel cervical corpectomy. Spine (Phila Pa 1976) 28:140-142, 2003

16. Smith GW, Robinson RA: The treatment of certain cervicalspine disorders by anterior removal of the intervertebral disc and interbody fusion. J Bone Joint Surg Am 40-A:607-624, 1958

17. Swank ML, Lowery GL, Bhat AL, McDonough RF: Anterior cervical allograft arthrodesis and instrumentation: multilevel interbody grafting or strut graft reconstruction. Eur Spine J 6:138143, 1997

18. Thome C, Leheta O, Krauss JK, Zevgaridis D: A prospective randomized comparison of rectangular titanium cage fusion and iliac crest autograft fusion in patients undergoing anterior cervical discectomy. J Neurosurg Spine 4:1-9, 2006

19. Topuz K, Colak A, Kaya S, Simsek H, Kutlay M, Demircan $\mathrm{MN}$, et al: Two-level contiguous cervical disc disease treated with peek cages packed with demineralized bone matrix: results of 3-year follow-up. Eur Spine J 18:238-243, 2009

20. Uribe JS, Sangala JR, Duckworth EA, Vale FL: Comparison between anterior cervical discectomy fusion and cervical corpectomy fusion using titanium cages for reconstruction: analysis of outcome and long-term follow-up. Eur Spine J 18:654-662, 2009

21. Vavruch L, Hedlund R, Javid D, Leszniewski W, Shalabi A: A prospective randomized comparison between the cloward procedure and a carbon fiber cage in the cervical spine: a clinical 
and radiologic study. Spine (Phila Pa 1976) 27:1694-1701, 2002

22. Wang JC, McDonough PW, Endow KK, Delamarter RB: A comparison of fusion rates between single-level cervical corpectomy and two-level discectomy and fusion. J Spinal Disord 14:222225, 2001

23. Wang JC, McDonough PW, Endow KK, Delamarter RB: Increased fusion rates with cervical plating for two-level anterior cervical discectomy and fusion. Spine (Phila Pa 1976) 25:41-45,
2000

24. White AA $3^{\text {rd }}$, Southwick WO, Deponte RJ, Gainor JW, Hardy R: Relief of pain by anterior cervical-spine fusion for spondylosis. A report of sixty-five patients. J Bone Joint Surg Am 55: 525-534, 1973

25. Yonenobu K, Fuji T, Ono K, Okada K, Yamamoto T, Harada $\mathrm{N}$ : Choice of surgical treatment for multisegmental cervical spondylotic myelopathy. Spine (Phila Pa 1976) 10:710-716, 1985 